\title{
STRATEGI IDENTIFIKASI DAN PEMETAAN TALENTA PADA BRANCH MANAGER SEBAGAI BAGIAN DARI SISTEM MANAJEMEN TALENTA
}

\author{
Muhammad Haris Novianto ${ }^{1}$ dan Artiawati $^{2}$ \\ ${ }^{1,2}$ Fakultas Psikologi - Universitas Surabaya \\ Jl. Tenggilis Mejoyo, Kali Rungkut, Kec. Rungkut, Surabaya, Jawa Timur 60293 \\ Email: psiko.haris@gmail.com
}

Diserahkan 23 Januari 2019; Diterima 29 Maret 2019; Dipublikasikan 01 April 2019

\begin{abstract}
ABSTRAK
Bagian awal sistem manajemen talenta adalah perumusan strategi identifikasi dan pemetaan talenta. Tujuan penelitian ini untuk menyusun strategi identifikasi dan pemetaan talenta. Metodologi penelitian menggunakan research and development yaitu berupa produk strategi identifikasi dan pemetaan talentapada brarnch manager. Hasil penelitian merumuskan strategi identifikasi talenta didasarkan pemenuhan kriteria pada tiga aspek pengukuran yaitu aspek potensial, yaitu kemampuan kognitif (general cognitive ability) dan kepribadian (personality), aspek kompetensi inti (agility, integrity, professional, achievement orientation, interpersonal sensitivity, dan teamwork) dan kompetensi spesifik (adaptability, working standard, communication skill, innovation and creativity, business acumen, problem solving, planning and organizing, continuous improvement, customer focus, relationship building, team leadership, developing others, negotiation skill dan computer literacy), serta aspek kinerja untuk key performance indicators. Perumusan strategi pemetaan talenta didasarkan pada kategori high potential dengan fitness potential profile diatas $90 \%$ dikategorikan sebagai high competence dengan fitness competency profile lebih dari $95 \%$ dan high performance dengan fitness performance profile lebih atau sama dengan $100 \%$.
\end{abstract}

Kata Kunci: Branch Manager, Kompetensi, Manajemen Talenta, Performance, Potensi, Strategi Identifikasi dan Pemetaan Talenta.

\section{IDENTIFICATION STRATEGY AND TALENT MAPPING TOWARD BRANCH MANAGER AS A PART OF MANAGEMENT TALENT SYSTEM}

\begin{abstract}
The first step of talent management system is designing strategies of talent identification and mapping. The purpose of this study was to design a strategy for identifiying and mapping talent in branch manager. The methodology using research and development that it's developing talent identification and mapping strategies. The resultsof study a formulated a talent identification strategy based on fulfilling the criteria in three measurement aspects, that potential aspect; general cognitive abilities and personality, core competencies (agility, integrity, professional, achievement orientation, interpersonal sensitivity, and teamwork) and specific competencies (adaptability, working standard, communication skills, innovation and creativity, business acumen, problem solving, planning and organizing, continuous improvement, customer focus, relationship building, team leadership, developing others, negotiation skills and computer literacy), and performance aspects in achieving key performance indicators. Designing of talent mapping strategies is based on categories high potential as fitness potential profile above 90\%, high competence as fitness competency profile above $95 \%$ and high performance as fitness performance profile above or equal $100 \%$.
\end{abstract}

Keywords: Branch Manager, Competencies, Talent Identification and Mapping Strategies,Performance, Potential, Talent Management.

\section{PENDAHULUAN}

Istilah manajemen talenta merupakan salah satu persoalan yang sudah lama menjadi topik sasaran yang terus dikaji dan dikembangkan baik dari kalangan akademisi maupun praktisi terutama di dunia industri untuk para human resource (HR), guna menjawab permasalahan-permasalahan yang terjadi di perusahan terkait dengan pemenuhan strategi dan target bisnis perusahaan. Persoalan manajemen talenta memang menjadi satu hal yang penting dalam menjawab persoalan kebutuhan perusahaan terutama dalam hal mencapai keuntungan atau target bisnis perusahaan. Pada manajemen talenta merupakan serangkaian aktivitas dan proses yang meliputi pengidentifikasian secara sistematis pada posisi kunci yang mana menunjukkan kontribusi secara berbeda pada pencapaian keuntungan organisasi, pengembangan dari suatu talent pool dan kinerja tinggi dari pemegang suatu jabatan (pegawai) untuk perannya dalam organisasi, dan pengembangan dari suatu pembeda untuk sumber daya manusia sebagai fasilitas untuk jenjang karir dengan pegawai 
yang kompeten dan untuk memastikan komitmen secara berkelanjutan terhadap organisasi (Collings dan Mellahi, dalam Torgersen dan Vatne, 2014). Lawler (2008) dan Michaels, et al. (2001) menyampaikan bahwa ada beberapa pendapat yang menyatakan bahwa talenta yang kuat dalam suatu perusahaan memiliki pengaruh positif terhadap pendapatan bisnis perusahaan.

Becker dan Huselid (dalam Yarnall, 2008) juga telah melakukan penelitian terhadap lebih dari 2.800 perusahaan yang sedang menerapkan dan menargetkan untuk strategi talenta, menunjukkan bahwa proses dalam memperbaiki praktik sumber daya manusia dapat memberikan dampak yang signifikan terhadap nilai pasar. Manajemen talenta yang terintegrasi dan secara progresif memiliki nilai pasar hingga $65 \%$ lebih tinggi. Hal yang menjadi penting dalam strategi talenta adalah implementasi strategi yang sampai pada pemunculan dampak daripada isi dari strategi itu sendiri. Butter, dkk (dalam Sabuncu dan Karacay, 2016) menjelaskan bahwa konsep talenta merupakan gabungan arti, yakni berarti memiliki kemampuan, kecerdasan dan kemampuan dalam berbagai profesi yang memungkinkan dilakukannya tindakan tertentu. Secara umum, talenta terutama merujuk pada tingkat kecerdasan seseorang atau kemampuan yang memungkinkan dengan mudah dan terampil melakukan aktivitas (Butter, dkk dalam Sabuncu dan Karacay, 2016).

Seringkali talenta dikaitkan dengan kemampuan, namun talenta itu sendiri juga dapat dikembangkan melalui latihan secara berkesinambungan. Sementara pegawai yang merunjuk pada diri seorang talenta memiliki efek strategis yang serupa terhadap kinerja dan daya saing perusahaan di berbagai sektor, namun pada identifikasi strategis yang menjadi ciri dari pegawai yang merupakan talenta di setiap industri menjadi sangat berbeda (Sabuncu dan Karacay, 2016). Oleh karenanya, guna memudahkan dalam pendefinisian talenta yang dapat mengarah pada pencapaian kinerja hingga mencapai target perusahaan tentunya perlu dilakukan strategi identifikasi pada kompetensi talenta yang dapat menggambarkan atribut utama pegawai yang disebut talenta di suatu perusahaan.

PT. X merupakan perusahaan distribusi yang memiliki beberapa cabang dandipimpin oleh seorang branch manager. Posisi ini menjadi peran kunci dalam memberikan kontribusi pencapaian sasaran target bisnis di perusahaan. Penurunan omzet pada beberapa tahun sebelumnya, disebabkan pencapaian omzet di beberapa cabang tidak memenuhi target yang ditentukan perusahaan. Hal tersebut menunjukkan ketidaktercapaian hasil kerja dari branch manager. Perusahaan berkomitmen untuk menetapkan posisi branch manager sebagai kunci dalam pemenuhan target perusahaan yang dalam hal ini menjadi sudut pandang dari organisasi sebagai posisi talenta yang strategis baik untuk diidentifikasi maupun dikembangkan selanjutnya.

Talenta yang dipandang sebagai individu, berarti seseorang yang dapat membuat suatu perbedaan pada kinerja organisasi secara cepat atas kontribusi atau dalam kurun waktu yang panjang dengan menunjukkan level potensi tertinggi yang dimiliki (the highest levels of potential) (CIPD, dalam Torgersen dan Vatne, 2014). Perbedaan kinerja pada organisasi diindikasikan sebagai keunggulan pada individu sebagai talenta yaitu sejumlah kemampuan khas dari orang (bakat dari laki-laki atau perempuan seperti skills, knowledge, pengalaman, inteligensi, pengambilan keputusan, sikap, karakter dan dorongan). Talenta juga dapat termasuk kemampuan untuk belajar dan berkembang (Michaels, Handfield-Jones dan Axelford, dalam Torgersen dan Vatne, 2014).

Sekalipun sasaran target posisi talenta dan kriteria yang diharapkan perusahaan atas talenta sudah dirumuskan, namun persoalan tersebut akan menjadi kompleks ketika proses identifikasi dan pemataan belum ditentukan secara tepat. Banyak perusahaan menghabiskan banyak waktu dan usaha untuk melakukan identifikasi terhadap talenta dan memetakan sesuai kebutuhan atas sasaran strategis perusahaan (Silzer dan Dowell, 2010). Kriteria talenta ini nanti yang dapat diidentifikasi sebagai keunggulan individu dibandingkan lainnya untuk dapat mengarahkan pada pencapaian kinerja unggul serta keahlian yang lebih tinggi. Oleh karenanya, aspek kompetensi dan kinerja menjadi salah satu fokus dalam menentukan kriteria talenta di perusahaan.

Ada beberapa pendekatan dalam perumusan strategi talenta untuk mendapatkan keselarasan strategi bisnis perusahaan. Competency model menjadi salah satu pendekatan dalam perumusan strategi talenta. Competency model merupakan sekumpulan daftar pengetahuan, keterampilan dan atribut lainnya (KSAOs) yang valid, dapat diamati, diukur dan ditunjukkan melalui perilaku yang menghasilkan kinerja unggul dalam konteks pekerjaan tertentu (Cernusca dan Dima, dalam Chouhan dan Srivastava, 2014). Competency model merupakan seperangkat kompetensi yang mencakup perilaku kunci yang diperlukan untuk melakukan pekerjaan secara unggul dalam peran tertentu (Cernusca dan Dima, dalam Chouhan dan Srivastava, 2014). Model ini disusun dalam tingkatan kompetensi atau kompleksitas tuntutan kemampuan dan mencakup deskripsi kegiatan atau perilaku yang terkait dengan setiap kompetensi.

Tujuan dari proses identifikasi dan pemetaan talenta, nantinya dapat memberikan gambaran prediksi mengenai performance talenta itu sendiri baik untuk saat ini maupun untuk di masa depan. Campbell (dalam Sonnentag, 2002) menjelaskan bahwa konsep performence dapat dibedakan atas dua hal, yakni aspek tindakan (perilaku) dan aspek hasil (outcomes). Performance pada aspek hasil (outcomes) merujuk pada konsekuensi atau hasil dari perilaku individu yang juga bergantung pada faktor-faktor tertentu daripada perilaku individu itu sendiri (Sonnentag, 2002). Outcomes performance ini nantinya yang menjadi rambu-rambu bagi individu dalam melakukan tindakan kerja/action/behavior performance ke depannya bila mengetahui hasil dari kinerjanya sudah terpenuhi atau tidak. Konteks pembahasan pada penelitian ini untuk action behavior adalah kompetensi. 
Ukuran keberhasilan organisasi secara spesifik dapat ditunjukkan pada pencapaian key perfromance indicators (KPI) yang dijelaskan oleh Parmenter (2007) sebagai representasi dari kumpulan pengukuran yang berfokus pada aspek-aspek kinerja dari organisasi yang paling banyak kritikal untuk saat ini dan kesuksesan di masa akan datang pada organisasi. Perilaku yang mengarah pada pencapaian hasil kerja atau dalam hal ini adalah kompetensi merupakan karakteristik yang mendasari individu secara kausal terkait dengan kriteria yang direferensikan efektif dan atau kinerja unggul dalam suatu pekerjaan atau situasi (Spencer dan Spencer, 1993). Kedua istilah ini nanti akan menjadi salah satu kriteria dalam penentuan talenta.

Talenta potensial juga diidentifikasikan pada segmentasi tertentu yang sesuai dengan potensi individu yang dapat bekerja secara maksimal. Talenta yang menunjukkan potensinya yang unggul,nantinya akan mendapatkan akses untuk diberikan pelatihan dan peluang program pengembangan yang akhirnya pada perencanaan karir ke depan pada posisi yang lebih tinggi dan tanggung jawab yang lebih kompleks beserta dengan kompensasinya (Meyers and Woekom, 2014). Potensi merupakan kondisi yang ada pada diri individu yang memungkinkan individu dapat menjadi lebih mudah dan cepat untuk belajar dan berkembang dari apa yang ada saat ini (Silzer dan Dowell, 2010). Dimensi potensial yang secara spesifik dapat dilakukan asesmen pada dimensi untuk cakupan potensi yang stabil seperti kemampuan berfikir (general cognitive ability) dan kepribadian (personality) yang mana faktor ini sangat diperlukan untuk berbagai peran dan posisi organisasi di masa depan (Silzer and Church, 2009).

Proses selanjutnya dari identifikasi adalah pemetaan talenta yang merupakan tindakan untuk meneliti personil dengan suatu kriteria tertentu untuk membangun profil masing-masing kandidat. Tindakan ini memberikan gambaran berharga dan juga memberikan pemahaman akan aktivitas apa yang hendak dilakukan terhadap para kandidat (Beheshtifar dan Kamani-Fard, 2013). Boudreau dan Ramstad (2005) membahas logika yang dapat diterapkan pada pembentukan kumpulan talenta (talent pool), dimana talent pool yang dibuat untuk pekerjaan, peran atau kompetensi dalam suatu organisasi dapat meningkatkan $20 \%$ kualitas atau ketersediaan yang membuat perbedaan pada keberhasilan organisasi. Talent pool adalah sekelompok orang yang dapat diketahui kesiapan dalam memikul tanggung jawab. Orang yang ditempatkan dalam talent pool mungkin muncul dengan berbagai kemampuan. Pendekatan dalam memasukkan sekelompok orang dalam talent pool adalah dengan melakukan evaluasi terlebih dahulu di mana pegawai yang dievaluasi memungkinkan akan berguna dan mampu bertanggung jawab di masa depan (Rothwell, 2006).

Penelitian ini bertujuan untuk membuat rumusan strategi identifikasi dan pemetaan talenta pada posisi branch manager di PT. X sebagai bagian dari pelaksanaan sistem manajemen talenta. Manfaat penelitian ini untuk memberikan bahan evaluasi pada perusahaan nantinya dalam melakukan identifikasi dan pemetaan talenta berdasarkan rumusan strategi identifikasi dan pemetaan telante berbasis kompetensi sehingga perusahaan dapat melakukan tahapantahapanselanjutnya pada sistem manajemen talenta sepertisuccession planning, talent development hingga pada talent retention. Di samping itu, perluasan kajian padastrategi identifikasi dan pemetaan talenta berdasarkan aspek potensi, kompetensi dan kinerja dapat menjadi kontribusi terhadap kajian manajemen talenta.

\section{METODE}

Penelitian ini menggunakan pendekatan research and development $(\mathrm{R} \& \mathrm{D})$ yaitu metode penelitian yang digunakan untuk menghasilkan produk tertentu dan menguji kefektifan produk tersebut (Sugiyono, 2017). Desain penelitian untuk research and development $(\mathrm{R} \& \mathrm{D})$ menggunakan pendekatan ADDIE (analysis, design, development, implementation dan evaluation) (Brach, dalam Sugiyono, 2017). Produk yang dihasilkan berupa rumusan strategi identifikasi dan pemetaan talenta, yaitu melingkupi pada tahapan analysis dan design produk terkait dengan general cognitive ability, personality, core comepetencies, specific competencies dan performance outcomes. Responden dalam penelitian ini adalah pegawai untuk posisi supervisor sales, kepala depo, branch manager dan regional manager yang merupakan jabatan untuk jalur karir dari target posisi talenta yaitu branch manager.

Proses asesmen dan penyusunan rancangan intervensi dalam penelitian ini, dilakukan dengan pendekatan kualitatif yaitu melalui penggalian data melalui wawancara, analisa dokumen dan kajian terhadap literatur yang mendukung. Sedangkan pada proses validasi terhadap hasil produk dilakukan dengan pendekatan kuantitatif yang ditujukan untuk menilai seberapa tepat hasil desain produk terhadap kebutuhan lapangan dan kebermanfaatan hasil desain produk melalui penilaian ahli yang dihitung dengan content validity index (CVI) (Lynn, 1986; Davis, 1997; Grant dan Davis, 1997) dan ditunjukkan dengan nilai prosentase index CVI. Anggota panel yakni pihak perusahaan diminta untuk menilai instrumen dalam hal kejelasan dan relevansinya terhadap konstruk yang mendasari studi sesuai definisi teoritis dari konstruk itu sendiri dan dimensinya pada skala ordinal yaitu 1 sampai dengan 4 (Davis, 1992). Penilaiannya adalah 1 berarti tidak relevan, 2 berarti agak relevan, 3 berarti relevan dan 4 berarti sangat relevan. Penelitian ini mempertimbangkan $80 \%$ persetujuan atau lebih tinggi diantara para panel untuk instrumen baru (Davis, 1992). Penilaian pada masing-masing item dibuat sebagai berikut; jika I-CVI lebih tinggi dari $79 \%$, item tersebut akan sesuai. Jika antara $70 \%$ sampai $79 \%$, itu perlu revisi. Jika kurang dari $70 \%$ berarti dihilangkan (Abdollahpour, et al., 2010). Aspek penilaian pada strategi identifikasi dan pemetaan talenta meliputi;rancangan strategi talenta, definisi profil jabatan talenta, identifikasi profil tugas dan tanggung jawab talenta, identifikasi profil key performance indicators (KPI) 
talenta, identifikasi profil potensi kemampuan berfikir (general cognitive ability), identifikasi profil potensi kepribadian (personality) talenta, identifikasi profil kompetensi inti (core) talenta, identifikasi profil kompetensi spesifik (specific) talenta, identifikasi instrumen pengukuran intelligence test talenta dengan culture fair intelligence test (CFIT), identifikasi instrumen pengukuran personality test talenta dengan DISC (dominant, influence, steady, dan complience) test, identifikasi instrumen pengukuran kompetensi baik inti dan spesifik dengan behavior based interview (BBI), leaderless group discussion (LGD), dan writing case analysis, identifikasi instrumen penugukuran hasil kinerja dengan key performance indicators, pemetaan kinerja (outcomes) dan kompetensi (actions) untuk pemetaan human asset value (HAV), pemetaan kompetensi dan potensi untuk pemetaan talent matrix, dan rancangan pemetaan pengembangan talenta berdasarkan kriteria potensi, kompetensi dan kinerja.

\section{HASIL DAN PEMBAHASAN}

Hasil penelitian mendapatkan rumusan mengenai strategi identifikasi tugas dan tanggung jawab branch manageryang meliputihalsebagaiberikut:

1) manajemen distribusi yaitu merencanakan, melaksanakan, memastikan dan mengendalikan atas realisasi program distrubusi sesuai dengan strategi penjualan dari regional manager (RM)yang ditetapkan agar memperoleh sistem distribusi yang responsif dan mencapai pertumbuhan usaha yang terus meningkat dan menguntungkan untuk lingkup cabang utama dan pembantu yang bersifat bulanan,

2) manajemen anggaran yaitu mengelola anggaran pada cabang utama dan pembantu dalam rangka mengoptimalkan sumber daya yang ada serta agar tercapainya pengendalian biaya perusahaan,

3) manajemen sumber daya manusia yaitu mengelola tenaga kerja untuk mencapai sasaran kerja bawahan pada cabang utama dan pembantu yang telah ditentukan mulai dari perencanaan kebutuhan tenaga kerja, aktivitas kerja (activity plan), penilaian terhadap kinerja bawahan hingga pada pengembangan kinerja bawahan melalui penegakan aturan kedisiplinan kerja serta pemberian program coaching-counseling-mentoring,

4) hubungan eksternal yaitu membina hubungan dengan pihak-pihak berwenang yang terkait dan dengan relasi bisnis (para principle) yang ada pada cabang utama dan pembantu dalam rangka menjaga citra perusahaan serta mempertahankan hubungan bisnis yang telah terjadi,

5) manajemen laporan yaitu me-review atas pencapaian kinerja di cabang utama dan pembantu terhadap target dan activity plan yang sudah disusun dan mempertanggung jawabkan dalam bentuk laporan pencapaian kerja secara periodik (mingguan dan bulanan) kepada regional manager sebagai rangka proses perbaikan dan evaluasi tercapainya tujuan perusahaan,

6) financeandaccounting yaitu monitoring account and recievable, asset perusahaan di setiap cabang dalam rangka lancarnya piutang dan menganalisa hasil laporan keuangan pada lingkup cabang utama dan pembantu,

7) manajemen logistik yaitu mengelola dan mengendalikan pendistribusian produk kepada pelanggan dan produk jadi di gudang serta mengkoordinasikan dengan setiap pimpinan cabang utama dan pembantu akan kebutuhan produk dalam rangka memastikan produk di pasar, dan

8) manajemen improvement yaitu memfasilitasi, memonitor dan memastikan pengembangan kinerja seluruh tim di setiap cabang utama dan pembantu melalui improvement berupa ide, gagasan atau pemikiran dalam rangka perbaikan di depertament distribusi.

Rumusan mengenai strategi talenta didasarkan pada kebutuhan perusahaan untuk pemenuhan talenta untuk sumber daya dari internal dan menerapkan sistem building talent strategy yaitu mengidentifikasi dan memetakan talenta serta mengembangkan talenta dari internal untuk memenuhi kebutuhan strategi perusahaan melalui agenda succession planning dan talent development. Rumusan strategi identifikasi dan pemetaan talenta, yaitu pada aspek potensi untuk inteligensi yaitu pengukuran dengan menggunakan culturefairintelligencetest(CFIT skala 3B) yang ditentukan dengan skor IQ diatas 110 dengan kategori di atas rata-rata sebagai talenta seorang branchmanager. Ketentuan aspek inteligensi lainnya yaitu sistematika berfikir pada subtes pertama dengan skor murni $>7$, ketajaman diferensiasi pada subtes kedua dengan skor murni $>7$, asosiasi pada subtes ketiga dengan skor murni $>7$ dan pemahaman konsep pada subtes keempat dengan skor murni $>5$. Pada aspek potensi kepribadian yaitu pengukuran dengan DISC test mensyaratkan pada fitness personality profile untuksuperior performer dengan ketentuan $>90 \%$ dengan berdasarkan job roles model. Fitness personality profile mengacu pada hasil nilai akhir gap antara publicdanself yang ada pada nilai bagian change DISC. Pemetaan hasil akhir pada aspek potensi untuk menunjukkan talenta pada branch manager yaitu high potentialdengan fitness potential profile $>90 \%$, dengan ketentuan perhitungan perbandingan rasio antara general cognitive ability dan personality adalah 30:70.

Strategi identifikasi dan pemetaan pada aspek kompetensi yaitu core competencies terbagi atas tiga kelompok kompetensi inti yaitu kelompok pertama personal capability terdiri atas agility competency yang memiliki indikator bertindak dengan kesadaran diri dan tetap berjuang mencapai tujuan sekalipun ada kesulitan, serta integrity competency yang memiliki indikator mengarahkan tindakan dalam mencapai tujuan kerja yang jelas dan tetap bertindak sesuai dengan norma dan aturan yang berlaku. Kelompok kedua goal orientation terdiri atas professional competency yang memiliki indikator dapat menentukan skala prioritas dan bertanggung jawab dalam memberikan hasil kerja terbaik, 
serta achievement orientation competency yang memiliki indikator berkontribusi lebih kepada perusahaan dan bersatu sebagai satu kesatuan. Kelompok ketiga social capabilityyang terbagi atas interpersonal sensitivity competency yang memiliki indikator memahami orang lain dan berfikiran terbuka serta menunjukkan rasa empati, dan teamwork competency yang memiliki indikator bersikap adil dan menghargai perbedaan serta mementingkan kepentingan bersama.

Level penguasaan corecompetenciesterdiri atas lima level yang mengacu pada dimensi kompleksitas yang dapatdigambarkandalam Table 1.

Tabel 1. Core Competencies

\begin{tabular}{|c|l|l|}
\hline Level Kompetensi & Kriteria & \multicolumn{1}{c|}{ Keterangan } \\
\hline 1 & Basic & penguasaan sebatas konsep sederhana dan pelaksanaan umum \\
\hline 2 & Proficient & penguasaan konsep dasar dan pelaksanaannya secara mandiri \\
\hline 3 & Advanced & penguasaan konsep yang kompleks dan implementasi secara optimal \\
\hline 4 & Expert & penguasaan konsep yang kompleks dan implementasi yang dapat efektif dan efisien \\
\hline 5 & Master & penguasaan konsep keseluruhan dan menjadi role model bagi lainnya \\
\hline
\end{tabular}

Model fit yang dirumuskan berdasarkan kesepakatan oleh panel dari perusahaan yaitu standar level penguasaan talenta pada posisi branch manager yaitu agility (level 4) dengan bobot kompetensi $15 \%$, integrity (level 4) dengan bobot kompetensi 20\%, professional (level 4) dengan bobot kompetensi $15 \%$, achievement orientation (level 4) dengan bobot kompetensi $15 \%$, interpersonal sensitivity (level 5) dengan bobot kompetensi $20 \%$ dan teamwork (level 4) dengan bobot kompetensi $15 \%$.

Pemenuhan specific competencies yang terbagi atas empat kelompok kompetensi spesifik yaitu kelompok personal mastery terdiri atas adaptability competency yang memiliki indikator menyesuaikan diri pada berbagai situasi dan tanggap dalam menyikapi persoalan untuk bekerja efektif, working standard competency yang memiliki indikator bekerja sesuai peraturan, prosedur atau standar ketentuan dan fokus terhadap setiap detail untuk mendapatkan hasil yang akurat, serta communication skill competency yang memiliki indikator menyampaikan bahan materi dan menyampaikannya secara logis dan persuasif serta mengatasi berbagai persoalan pertanyaan dan situasi sulit saat menyampaikan. Kelompok kedua business masteryterdiri atas innovation and creativiycompetency yang memiliki indikator menghasilkan dan menerapkan metode penyelesaian yang inovatif serta melakukan terobosan baru sebagai bentuk pengembangan dan peningkatan kinerja, business acumencompetency yang memiliki indikator mengenali potensi-potensi bisnis yang dapat memberikan kontribusi terhadap peningkatan bisnis perusahaan serta menindaklanjuti potensi-potensi bisnis yang ada sehingga dapat direalisasikan, problem solving competency yang memiliki indikator memahami persoalan dengan berdasarkan data atau fakta serta menggunakan konsep yang dimiliki dan memutuskan alternatif penyelesaian terhadap masalah dengan pertimbangan atas risiko putusan, planning and organizing competency yang memiliki indikator merencanakan tindakan kerja dan mengelola sumber daya yang ada serta mengawasi dan mengeveluasi terhadap proses dan hasil pelaksanaan kerja, continuous improvement competency yang memiliki indikator mengenali kebutuhan akan perbaikan dan merancang strategi pembenahan terhadap hasil kerja serta perbaikan secara terus menerus sehingga mendapatkan hasil kerja yang lebih baik, customer focus competencyyang memiliki indikator peduli, memahami, mengantisipai kebutuhan pelanggan dan memberikan pelayanan serta membangun dan menjaga loyalitas pelanggan, dan relationship building competency yang memiliki indikator mengenali peluang membuka hubungan kerjasama/jaringan yang bernilai strategis dan mempertahankan dan membangun hubungan kerjasama/jaringan yang strategis. Kelompok ketiga leadership masteryyang terbagi atas team leadership competency yang memiliki indikator mengarahkan orang lain dalam kinerja kelompok dan menggerakkan orang lain untuk menjalankan tugas dalam memenuhi tujuan, sertadeveloping otherscompetency yang memiliki indikator menetapkan sasaran program pengembangan bagi orang lain serta mengajarkan dan mengembangkan orang lain. Kelompok keempat technical mastery yang terbagi atas negotiation skill competency yang memiliki indikatoryang memiliki indikator mengklarifikasi permasalahan sesuai dengan bagiannya, menyesuaikan strategi dan mengelola konflik yang terjadi, dan membangun kesepakatan bersama, dan computer literacy competency yang memiliki indikator mengelola informasi atau data dalam aplikasi komputer sesuai kebutuhan dan mengakses informasi atau data dalam aplikasi komputer sesuai kebutuhan.

Level penguasaan pada specific competencies mengacu pada dua dimensi dengan lima level penguasaan yaitu dimensi kompleksitas dan dimensi ukuran dampak. Pada dimensi kompleksitas yaitu level 1 basic;penguasaan sebatas konsep sederhana dan pelaksanaan umum, level 2 proficient;penguasaan konsep dasar dan pelaksanaannya secara mandiri, level 3 advanced;penguasaan konsep yang kompleks dan implementasi secara optimal, level 4 expert;penguasaan konsep yang kompleks dan implementasi yang dapat efektif dan efisien, serta level 5 master;penguasaan konsep keseluruhan dan menjadi role model bagi lainnya. 
Pada dimensi level penguasaan ukuran dampak yaitu level 1 eksekusi; dasar penguasaan pelaksanaan kerja sesuai konsep pemahaman, level 2 pribadi; pelaksanaan kerja untuk optimalisasi pada lingkup tugas pribadi, level 3 kelompok; pelaksanaan kerja untuk optimalisasi pada lingkup kelompok, level 4 unit kerja; pelaksanaan kerja untuk optimalisasi pada lingkup unit kerja dan level 5 korporasi; pelaksanaan kerja untuk optimalisasi pada lingkup korporasi. Model fit yang dirumuskan berdasarkan kesepakatan oleh panel dari perusahaan yaitu standar level penguasaan talenta pada posisi branch manager yaitu adaptability(level 4) dengan bobot kompetensi 5\%, working standard(level 4) dengan bobot kompetensi 5\%, communication skill (level 4) dengan bobot kompetensi $10 \%$, innovation and creativity(level 4) dengan bobot kompetensi 5\%, business acumen(level 5) dengan bobot kompetensi $10 \%$, problem solving(level 4) dengan bobot kompetensi $10 \%$, planning and organizing (level 4) dengan bobot kompetensi $10 \%$, continuous improvement (level 4) dengan bobot kompetensi 5\%, customer focus (level 4) dengan bobot kompetensi 5\%, relationship building (level 4) dengan bobot kompetensi $10 \%$, team leadership (level 4) dengan bobot kompetensi 10\%, developing others (level 4) dengan bobot kompetensi 5\%, negotiation skill (level 4) dengan bobot kompetensi 5\%, dan computer literacy (level 3) dengan bobot kompetensi 5\%. Pemetaan hasil akhir pada aspek kompetensi menunjukkan pada talenta untuk branch manager yaitu high competence dengan fitness competency profile > 95\%, dengan ketentuan perhitungan perbandingan rasio antara core competencies dan specific competencies adalah 30:70.

Outcomes based dengan pengukuran pada enam indikator kunci kinerja (KPI) dari branch manager yaitu target omzet dengan bobot penilaian $20 \%$, target accounting recievabledengan bobot penilaian $20 \%$, rugi laba dengan bobot penilaian $25 \%$, active outletdengan bobot penilaian $15 \%$, effective call dengan bobot penilaian $10 \%$ dan item per transaksi dengan bobot penilaian 10\%.Pemetaan hasil akhir pada aspek performance menunjukkan talenta untuk branch manager yaitu high performance dengan fitness performance profile $\geq 100 \%$. Ketentuan ini didasarkan pada pencapaian hasil kinerja sebelumnya dan hasil turunan dari target bisnis perusahaan di setiap cabang.

Berdasarkan hasil penilaian dari para ahli mengenai ketepatan dari penyusunan strategi identifikasi dan pemetaan talenta menunjukkan nilai I-CVI pada setiap item perumusan strategi identifikasi dan pemetaan talenta yaitu menunjukkan angka $>85 \%$ yang berarti hasil per item penyusunan strategi identifikasi dan pemetaan talenta dapat dikatakan tepat atau sudah sesuai. Selanjutnya, pada perhitungan hasil S-CVI menunjukkan angka $>80 \%$ yang berarti hasil per item secara keseluruhan telah sesuai dan tepat dalam penyusunan berdasarkan kajian teoritis dan kebutuhan di lapangan.

Spencer dan Spencer (1993) menjelaskan pada hasil penelitiannya yang dilakukan selama beberapa tahun mengenai kompetensi sebagai prediktor yang baik dalam menentukan job performance seseorang. Hal tersebut mengacu pada sekumpulan keterampilan dan kemampuan yang dapat ditunjukkan untuk memenuhi sejumlah pekerjaan dalam memenuhi kinerja unggul sebagai kompetensi (Spencer dan Spencer, 1993).Kompetensi sebagai actions performance merujuk pada dua hal yaitu task performance yang dapat memberikan kontribusi baik langsung maupun tidak langsung terhadap tujuan teknis organisasi dan contextual performance yang tidak mengarah pada tujuan teknis organisasi melainkan untuk mendukung organisasi, sosial dan lingkungan secara psikologis dalam mengejar target organisasi (Sonnentag, 2002). Istilah actions performance yang telah dirumuskan adalah kompetensi, yakni dibedakan atas core competencies untuk contextual performance dan specific competencies untuk task performance.

Perumusan core competencies didasarkan pada visi, misi, values dan rencana strategis yang menjadi dasar ketentuan untuk memunculkan perilaku kunci yang menggambarkan karakteristik perusahaan. Implementasinya di lapangan dan hasil penelitian lebih pada melakukan penjelasan lebih detail mengenai perilaku kunci dari operasional kompetensi yang telah dirumuskan beserta dengan level kompetensinya. Perumusan specific competencies berdasarkan pada penentuan kompetensi yang disyaratkan pada jabatan yang menjadi sasaran talenta yaitu branch manager atau kandidat branch manager atau setingkat jabatan untuk level diatasnya. Penurunan jenis kompetensi jabatan didasarkan pada strategi tugas dan tanggung jawab yang telah dirumuskan sebelumnya pada strategi identifikasi tugas dan tanggung jawab (job description) branch manager. Hal ini dikarenakan pada tugas dan tanggung jawab mensyaratkan adanya perilaku kunci yang menjadi sasaran dalam pemenuhan hasil, dan perilaku tersebut menggambarkan kompetensi seseorang. Kunci dari identifikasi talenta berdasarkan perilaku adalah mengamati dan menilai perilaku yang dapat ditentukan tingkat kemahiran pada dimensi perilaku itu sendiri (Thornton dan Byham, 1982).Penentuan kriteria, operasional dan standar level penguasaan didasarkan pada hasil kesepakatan dengan para panel pihak perusahaan sebagai pengambil keputusan yang menunjukkan adanya kebutuhan kompetensi dan kinerja di perusahaan (Spencer dan Spencer, 1993).

Desain instrumen yang ditentukan dalam perumusan startegi identifikasi kompetensi talenta mengacu pada hasil penelitian yang telah dilakukan sebelumnya mengenai prediktor terbaik dalam melakukan asesmen kompetensi untuk melihat job performance. Spencer dan Spencer (1993) memaparkan bahwa ada beberapa metode yang memiliki nilai korelasi terhadap job performance yaitu: 1) assessment centerdengan $\mathrm{r}=0,65,2)$ behavioral interviewdengan $\mathrm{r}=0,48$ - 0,61,3) exercise test (simulation) dengan $r=0,58,4)$ work sample testsdengan $\mathrm{r}=0,54,5)$ ability test (cognitive ability test) dengan $\mathrm{r}=0,39,6$ ) personality testdengan $\mathrm{r}=0,53,7$ ) biodatadengan $\mathrm{r}=0,38$, dan 8 ) referencesdengan $\mathrm{r}=0,23$. Pendekatan instrumen yang digunakan dalam asesmen kompetensi sebagai strategi identifikasi kompetensi adalah behavior based interview (BBI) dan exercise test berupa 
leaderless group discussion (LGD) dan writing case analysis yang didasarkan pada kasus yang dirumsukan dan sudah divalidasi oleh pihak perusahaan.

Konteks kompetensi yang sifatnya lebih mendalam (hidden area) merupakan unsur yang penting pula dalam menentukan seseorang untuk memunculkan keterampilan yang dimiliki atau tidak. Aspek ability, traits, attitude dan sebagainya menjadi salah satu poin penting dalam menentukan kompetensi seseorang menjadi unggul atau tidak.Kemampuan berfikir (general cognitive ability) memiliki andil yang cukup tinggi dalam menentukan performa seseorang dalam bekerja. Hal ini sejalan dengan yang disampaikan oleh Spearman (dalam Ruiz, 2009), general intelligence yang juga dikenal sebagi $g$ factor adalah kecenderungan bagi individu yang terbaik dalam satu hal untuk menjadi yang terbaik daripada yang lain (kemampuan seseorang dikatakan berkorelasi secara positif). Cattell dan Horn (dalam Gottfredson, 1997) mengidentifikasi dua komponen, yang diberikan label fluid intelligence $\left(\mathrm{g}_{\mathrm{f}}\right)$ dan crystallized intelligence $\left(\mathrm{g}_{\mathrm{c}}\right)$. Fluid intelligence $\left(\mathrm{g}_{\mathrm{f}}\right)$ merupakan sebagian besar bentuk efisiensi mental non verbal yang terkait dengan kapasitas seseorang untuk belajar dan memecahkan masalah baru. Sebaliknya crystallized intelligence $\left(\mathrm{g}_{\mathrm{c}}\right)$ mewakili apa yang sudah dimiliki seseorang, dipelajari melalui investasi dari fluid intelligence $\left(\mathrm{g}_{\mathrm{f}}\right)$ dalam setting budaya. $G$ factor pada dasarnya adalah kemampuan untuk menghadapi persoalan dengan kompleksitas kognitif, khususnya mengenai pemrosesan informasi yang kompleks (Gottfredson, 1997). Semakin kompleks suatu tugas, maka semakin besar keuntungan yang diberikan oleh $g$ factor dalam melakukan secara baik.

Interaksi antara kemampuan berfikir (general cognitive ability) dan keperibadian setidaknya lebih penting dalam mempengaruhi hasil kinerja seseorang (performance outcomes) daripada pengaruh atas kemampuan atau kepribadian secara terpisah. Hasil penelitian yang dilakukan Cattell dan Child (1975); Cattell dan Kline (1977) menunjukkan bahwa adanya korelasi yang cukup tinggi hingga 0,60 antara interaksi kemampuan berfikir (general cognitive ability) dan keperibadian terhadap hasil kinerja seseorang (performance outcomes) dibandingkan dengan korelasi antar kemampuan berfikir (general cognitive ability) dan keperibadian terhadap hasil kinerja seseorang (performance outcomes) yang terpisah yaitu memiliki nilai korelasi tidak sampai $r=0,30$.

Kepribadian merujuk pada suatu pola watak yang relatif permanen, dan sebuah karakter unik yang memberikan konsistensi sekaligus individualitas bagi perilaku seseorang (Feist dan Fesit, 2008). Perilaku yang ditunjukkan sebagai bentuk dari konsistensi karakter unik seseorang dapat mengarahkan pada pencapaian hasil tertentu. Hogan (2007) menyampaikan bahwa prediktor terbaik perilaku masa depan adalah perilaku masa lalu. Saat individu berhasil memenuhi kesuksesan atau keberhasilan tertentu dengan adanya pola perilaku tertentu, maka kecenderungan akan keberhasilan di masa depan akan terulang dengan adanya pola perilaku yang akan dimunculkan. Salah satu pendekatan tipikal dalam melihat kepribadian yaitu dengan model personality factor.

Pendekatan personality factor model yang digunakan adalah dominant, influence, steadinessdan complience (DISC) yang merupakan sebuah model yang mencerminkan perilaku orang dalam situasi konkrit dan dapat digunakan dalam situasi dan setting di tempat kerja (Marston, 1928). Konsep dasar DISC oleh Marston (1928) adalah kecenderungan individu dalam menampilkan gaya perilaku dengan menggunakan kerangka berfikir dari konsep kepribadian Jung.Marston melakukan extensive observational research terhadap characteristic, pattern, dan respondsdari ribuan orang dengan mempergunakan kerangka berfikir Jung. Marston (1928) menjelaskan bahwa bagaimana emosi seseorang yang normal menyebabkan perbedaan perilaku di antara mereka dan juga perubahan perilaku seseorang dari waktu ke waktu. DISC model memiliki beberapa keunggulan diantaranya adalah seringkali DISC model digunakan dalam urusan bisnis di organisasi sebagai salah satu alat prediksi dalam menentukan perilaku seseorang atau peran managerial dalam setting bisnis (Reynierse, et al., 2000). Deviney, et al. (2010) juga memaparkan bahwa DISC model telah terbukti menjadi prediktor keberhasilan di berbagai bidang seperti retensi pegawai, kesuksesan kerja, manajemen penjualan, dan mempersuasi klien untuk menerima rencana ajakan dan sebagainya.

Desain instrumen yang digunakan dalam pengukuran general cognitive ability melalui pengukuran fuild intelligence adalah menggunakan culture fair intelligence test (CFIT). Instrumen CFIT memiliki nilai reliablitas 0,91 untuk skala 2 dan 0,87 untuk skala 3. Sedangkan pada validitasnya menunjukkan nilai 0,92 pada validitas konsep dan 0,69 pada validitas konkrit (Cattel, 1977). Desain instrumen pengukuran kepribadian yang menggunakan DISC test menunjukkan pada hasil validitas dan reliabilitas DISC test yaitu dominance, influence, steadiness, dan complience dengan sig $<0,01$ dan reliabilitas $r>0,70$. Berdasarkan hasil uji instrumen yang telah dilakukan oleh peneliti sebelumnya dapat menjadi ketentuan dalam pemilihan instrumen untuk mengukur general cognitive ability dan personality.

Outcomes performance yang merupakan ukuran kinerja branch manager dirumuskan berdasarkan cascading dari target bisnis perusahaan yangditurunkan pada masing-masing pimpinan regional untuk diturunkan pada setiap pimpinan cabang. Hal ini sejalan dengan yang disampaikan oleh EvansObinna (2016) bahwa konsep penentuan target bisnis perusahaan yang diturunkan pada masing-masing unit merupakan konsep management by objective yaitu sebagai proses yang mengarahkan kinerja dalam mencapai target dan tujuan yang diatur pada setiap masing-masing subordinat pimpinan (manajer lini) untuk saling berkolaborasi dengan atasannya yang dimulai saat periode penilaian atau penentuan rencana. Proses penurunan atau cascading target bisnis didasarkan pada historis pencapaian target sebelumnya dan penilaian kemampuan cabang terkait. Penentuan ini sudah 
menjadi ketentuan dari perusahaan yang memiliki kewenangan dalam menentukan jumlah nilai target adalah regional manager untuk masing-masing pimpinan cabang. Penentuan atas bobot nilai dari setiap masing-masing faktor kinerja yang juga berbeda-beda ditentukan oleh perusahaan dengan pertimbangan atas cakupan tugas dan tanggung jawab yang dimiliki oleh setiap masing-masing jabatan. Semakin tinggi cakupan dan tanggung jawab terhadap operasional (pelaksanaan teknis di lapangan seperti supervisor) semakin besar proporsi yang diberikan dalam penilaian bobot pada faktor kinerja yang terkait dengan proses operasional teknis di lapangan dan seterusnya.

Berdasarkan hasil penelitian dan pembahasan di atas, maka dapat digambarkan mengenai alur kerja pada strategi identifikasi dan pemetaan talenta untuk posisi branch managerdengan merujuk pada framework talent management system dari Silzer dan Dowell (2010) dan disesuaikan dengan hasil analisis terhadap kesesuaian data di perusahaan, yaitu:

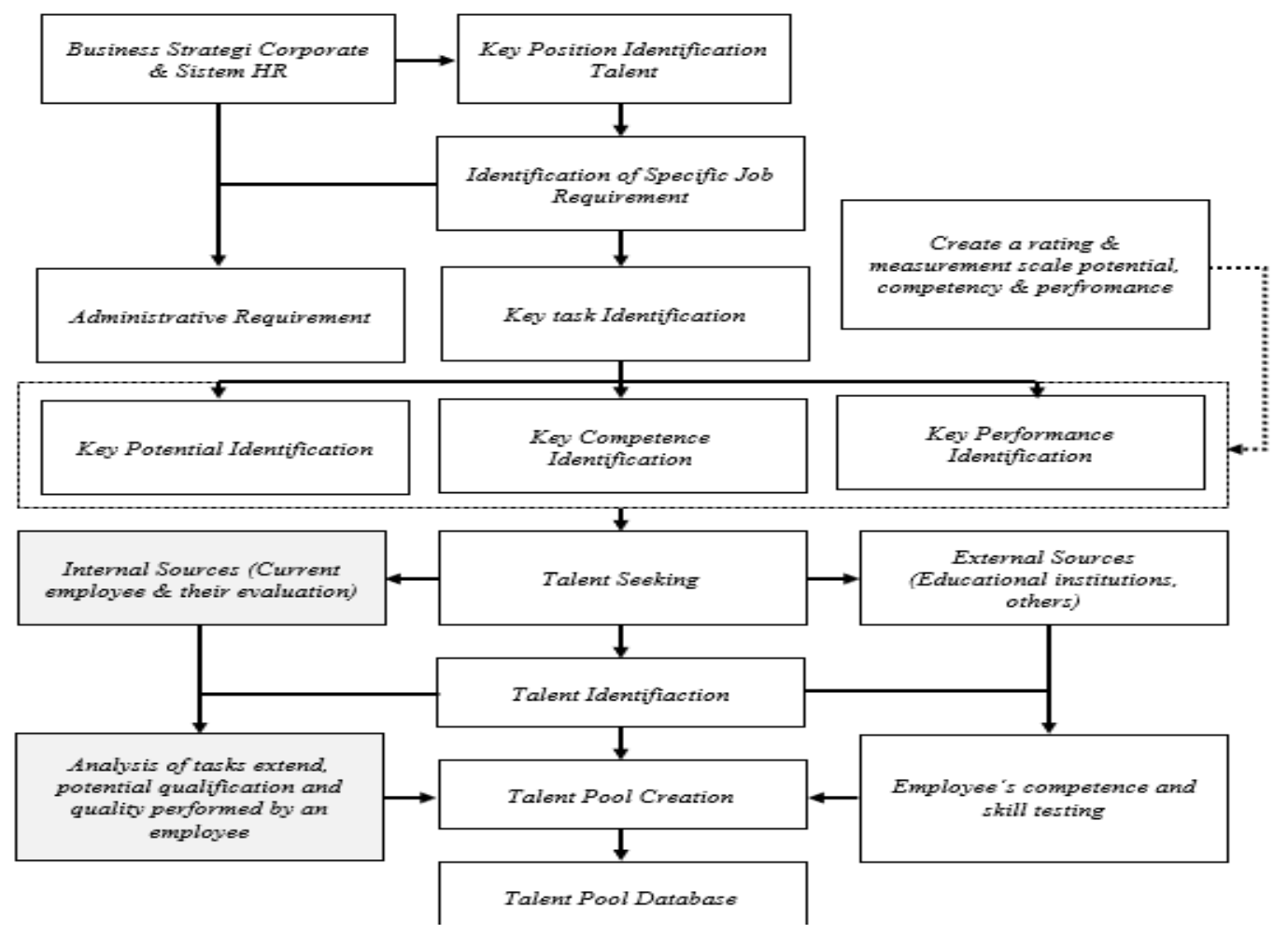

Gambar 1. Alur Strategi Identfiikasi dan Pemetaan Talenta

\section{SIMPULAN}

Strategi identifikasi dan pemetaan talenta merupakan bagian dari strategi talenta.Strategi talenta memiliki beberapa pendekatan. Penggunaan comptency model sebagai basis dalam menentukan strategi identifikasi dan pemetaan talenta menjadi fokus dalam penelitian. Integrasi dengan berbagai pendekatan strategi dapat mendukung kesempurnaan dalam perumusan strategi talenta seperti pendekatan bisnis yang erat dengan finance, pendekatan pengelolaan human resource dan pendekatan lainnya. Di samping itu, strategi identifikasi dan pemetaan talenta yang telah dibuat perlu dilakukan berbagai metode praktis untuk mendukung dalam penyempurnaan hasil strategi identifikasi dan pemetaan talenta disamping dengan kesepakatan para panel atau ahli terkait seperti identifikasi langsung pada superior performer pada kriteria kompetensi melalui penggalian dengan behavior based interview (BBI), identifikasi melalui expert systems dan melalui competencies requirements questionnaire (CQC). Hasil strategi identifikasi dan pemetaan talenta ini dapat dijadikan model fit dan dibuktikan melalui uji lapangan lanngsung untuk menindaklanjuti dari metode ADDIE sebagai development, implementasi dan evaluasi hasil produk.

Pemetaan talenta didasarkan pada pemenuhan tiga aspek potensi, kompetensi dan kinerja dengan nilai fitnesspada highcriteriayaitu diatas $90 \%$ pada aspek potensi, diatas $95 \%$ pada aspek kompetensi dandiatasatausamadengan $100 \%$ pada aspek hasil kinerja, yang didasarkan pada model superior performer ada $10-20 \%$ di suatu perusahaan sebagai talenta. Penentuan talenta selanjutnya didasarkan pada perhitungan kuantitatif yang disimpulkan pada penentuan kriteria administrasi pegawai untuk talenta yang telah ditentukan perusahaan seperti lama pengalaman kerja, historis penilaian kinerja selama 5 tahun terakhir dan tingkat 
pendidikan.Rumusan strategi identifikasi dan pemetaan talenta yang didasarkan pada competency model mengacu pada strategi bisnis perusahaan dengan menurunkan aktivitas kerja dan kompetensi yang disyaratkan dalam memenuhi target kerja untuk posisi branch manager. Hal ini menjadi fokus untuk menjawab kebutuhan perusahaan dalam menentukan talenta yang didasarkan pada sasaran target bisnis perusahaan melalui keunggulan talenta yang dimiliki atas potensi dan kompetensi yang disyaratkan dalam menghasilkan kinerja yang unggul.

\section{DAFTAR PUSTAKA}

Abdollahpour E, Nejat S, Nourozian M, and Majdzadeh R. (2010). The process of content validity in instrument development. Iranian Epidemiology; 6 (4): 66-74

Beheshtifar, M., dan Begom-Kamani-Fard, F. (2013). A talent pool: A main factor to success. Journal of Contemporary Research in Business, Vol 4, No. 12

Boudreau, J. W., dan Ramstad, P. M. (2005). Talentship, talent segmentation, and sustainability: A new HR decision science paradigm for a new strategy definition. Human Resource Management, 44: 129-136.

Chouhan, V. S., dan Srivastava, S. (2014). Understandaing competencies and competency modeling - A literature survey. IOSR Journal of Business and Management (IOSR-JBM). e-ISSN: 2278-487X, pISSN: 2319-7668. Volume 16, Issue 1. Ver. I (Jan. 2014), PP 14-22. www.iosrjournals.org

Cattell, R B. dan Cattell, A. K. S. (1977). Measuring Intelligence With The Culture Fair Tests. Champaign, Illinois: Institute for Personality and Ability Testing.

Davis LL. (1992). Instrument review: Getting the most from a panel of experts. Applied Nursing Research; 5 (4): 194-7. doi:10.1016/ S0897-1897 (05) 800 08-4

Deviney, D., Mills, L. H., dan Gerlich, R. (2010). Environmental impacts on GPA for accelerated schools: A values and behavioral approach. Journal Of Instructional Pedagogies, 31-15

Evans-Obinna, R. N. (2016). Management by objective: a top down planning technique for effective nigerian secondary school management in the $21^{\text {st }}$ century. International Journal of Education, Learning and Development Vol. 4, No. 3, pp. 70-81.

Feist, J. and Feist, G. J. (2008). Theories of Personality: Edisi Keenam. Yogyakarta: Pustaka Belajar
Gatewood, R. D., dan Feild, H. S. (2001). Human Resource Selection (5th ed.). Mason, $\mathrm{OH}$ : South Western

Grant JS, Davis LL. (1997). Selection and use of content experts for instrument development. Res Nurs Health; 20 (3): 269-74. doi: 10.1002 / (sici)1098$240 x$

Hogan, J., Barret, P., dan Hogan, R. (2007). Personality measurement, faking, and employment selection. Journal of Applied Psychology, 92, 1270-1285.

Lawler III, E. E. (2008). Talent: Making People Your Competitive Advantage. San Fransisco: Jossey-Bass.

Lynn MR. (1986). Determination and quantification of content validity. Nurs Res; 35 (6): 382-5

Mayers, M. C., and Woerkom, M. V. (2014). The influence of underlying philosophies on talent management: Theory implications for practice and research agenda. Journal of World Business, 49: 192-203.

Marston, W. M. (1928). Emotions of Normal People. New York: Harcourt, Brace and Compay.

Michaels, E., Handfield-Jones, H., and Axelrod, B. (2001). The War for Talent. Boston: Harvard Business School Press.

Parmenter, D. (2007). Key Performance Indicators; Developing, Implementing, and Using Winning KPIs. US of Amerika: John Wiley dan Sons, Inc.

Reynierse, J. H., Ackerman, D., Fink, A. A., dan Harker, J. B. (2000). The effects of personality and management role on perceived values in business settings. International Journal of Value - Based Management, $13(1), 1-13$

Rothwell, William J. (2006).Ten Key Steps to Effective Succession Planning. RothwelldanAssociates Inc. pp. 4-11.

Ruiz, P. E. (2009). Measuring fluif intelligence on a ratio scale: Evidance from nonverbal classification problems and information entropy. Behavior Research Methods, 41 (2), 4349-445

Sabuncu, K. U. and Karacay, G. (2016). Exploring professional competencies for talent management in hospitality and food sector in Turkey. Procedia Social and Behavioral Sciences(235), 443 - 452 
Jurnal Psikologi Sains dan Profesi (Journal Psychology of Science and Profession)

Vol. 3, No. 1, April 2019: 21-30

Silzer, R., and Church, A. H. (2009). The pearls and perils of identifiying potential. Industrial and Organizational Psychology: Perspectives on Science and Practice, 2: 3777-412.

Silzer, R. F. dan Dowell, B. (2010). Strategy-Driven Talent Management; A Leadership Imperative. San Fracisco : Jossey-Bass.

Sonnentag, S. (2002). Psychological Management of Individual Performance. United Kingdom: John Wiley dan Sons, Ltd.

Spancer, L., M. dan Spencer, S., M. (1993). Competence At Work: Model for Superior Performance. United States of Amerika: John Wiley dan Sons, Inc.

Jordan Hill, Oxford OX2 8DP.
Sugiyono. (2017). Metode Penelitian dan Pengembangan: Research and Development. Bandung : Alfabeta.

Thornton, G. C., III, \& Byham, W. C. (1982). Assessment Centers and Managerial Performance. New York: Academic Press

Torgersen, K. and Vatne, M. (2014). Talent management: "what is the value of talent management in business organizations?". Master Thesis. Handelshojskolen. Copenhagen Business School

Yarnall, J. (2008). Strategic Career Management Developing Your Talent. UK : Linacre House, 